\title{
2D Propagation Simulation of Variation Parameters of U-shape Fiber Optic
}

\author{
Noor Azie Azura Mohd Arif, Dilla Duryha Berhanuddin, Abang Annuar Ehsan
}

\begin{abstract}
Fiber optic has extraordinary properties and is suitable in sensor applications due to its special potential. Currently, macro bending characteristics of newly developed hetero core fiber optic element are designed and evaluated. This paper presents the preliminary results obtained from the numerical simulation analysis of the bending sensitivity of $U$-shape fiber optics toward the $2 D$ electromagnetic wave in terms of mesh, curvature radius, core fiber size, and turn number. Fiber optics with core sizes of $4,9,50$, and $62.5 \mu \mathrm{m}$ were designed. In addition, the combination of core diameters 50-4-50, 50-9-50, 62.5-4-62.5, and 62.5-9-62.5 $\mathrm{mm}$ is evaluated to compare the outcome of transmission power in terms of hetero core structure of fiber optic. Simulation is performed using COMSOL Multiphysics simulation tool. The developed $U$-shape fiber optic is designed to sense the distortion of reducing power transmission by comparing input and output power. Results show that the selected mesh depends on the size of geometry bending fiber optics, and fine and finer mesh is the best for $U$-shape fiber optic. Furthermore, the power flow on the fiber decreases with the decreasing curvature radius and increasing turn number. The fiber with a core size combination of 62.5-4-62.5 um has high sensitivity in terms of loss. The attained results possess higher potential in the field of sensor applications, such as displacement, strain, pressure, and monitoring respiration, on human body. This study serves as a basis for further investigation of nanomaterial coating on fiber optics, thereby enhancing its credibility for sensing.
\end{abstract}

Keywords: Wave optic, power flow, macro bending, hetero core, COMSOL Multiphysics.

\section{INTRODUCTION}

Bending optical fiber causing several powers and affects the transmission efficiency in applications. Numerous theoretical and experimental studies on bending effect have been conducted, such as studies on curvature radius, turn number, and bend structure. Researchers have attempted to eliminate loss to improve the efficiency of fiber optics. The bending structure has some good effects on special applications, such as on strain, displacement, and pressure

Revised Manuscript Received on December 25, 2020.

* Correspondence Author

Noor Azie Azura Mohd Arif*, Centre for Pre-university Studies, Universiti Malaysia Sarawak, 94300 Kota Samarahan, Sarawak, Malaysia. Email:manaazura@unimas.my

Dilla Duryha Berhanuddin, Institute of Microengineering and Nanoelectronics, Universiti Kebangsaan Malaysia, Malaysia. Email: dduryha@ukm.edu.my

Abang Annuar Ehsan, Institute of Microengineering and Nanoelectronics, Universiti Kebangsaan Malaysia, Malaysia. Email: aaehsan@ukm.edu.my

(C) The Authors. Published by Blue Eyes Intelligence Engineering and Sciences Publication (BEIESP). This is an open access article under the CC BY-NC-ND license (http://creativecommons.org/licenses/by-nc-nd/4.0/) sensors. The loss in bending structure enhances the sensor sensitivity and has a good impact on certain applications. Therefore, the preliminary results obtained from investigating the propagation through bending fiber optics are presented in this paper. The U-shape structure of fiber optics is considered to simulate bending at the macroscopic level in terms of mesh type, core diameter, turn number, and curvature radius.

\section{EFFECT OF STRUCTURAL CHARACTERISTICS}

\section{A. Effect of mesh size selection}

A free mapped mesh with an extremely fine element was chosen and calibrated for the fiber optics. All mesh sizes, namely, extremely fine, extra fine, finer, fine, normal, coarse, coarser, extra coarse, and extremely coarse, were tested to identify the size that can generate a perfect result. The result is usually perfect when an extremely fine mesh is used for long fibers.

\section{B. Effect of core diameter}

The mode field diameter is the most important in determining the susceptibility of the bending fiber that induces loss. A small mode field diameter indicates that light is tightly confined to the center of the fiber. That is, light is less likely to leak when the fiber is bent. In the bending fiber, the total number of modes can be related to the index profile, the propagating wavelength, and the radius of curvature as shown in (1)

$$
N_{\text {eff }}=N_{\infty}\left\{1-\frac{\alpha+2}{2 \alpha \Delta}\left[\frac{2 \alpha}{R}+\left(\frac{3}{2 n_{2} k R}\right)^{2 / 3}\right]\right\}
$$

where $N$ is the number of modes supported in a straight fiber, $\alpha$ defines the index profile, $\Delta$ is the core-cladding index difference, $n_{2}$ is the cladding index, $k=\frac{2 \pi}{\lambda}$, and $R$ is the radius of curvature of the bend [1].

\section{Effect of turn number}

Consequently, the power loss increases with the number of turns $(N)$, resulting in increased bend loss. The relationship between losses and $N$ can be simplified using

$$
L_{N}=\xi_{N} N
$$

where $L_{N}$ is the bending loss for a specific $N$, and $\xi_{N}$ is the fitting parameter due to $N$ [2].

\section{Effect of curvature radius}

\section{Published By:}




\section{D Propagation Simulation of Variation Parameters of U-shape Fiber Optic}

Bending loss has a direct relationship with the bending radius. The loss increases as the radius decreases. The radius of bending is an important parameter.

The bending measurement is used to determine the loss associated with it. Bend loss has a direct relationship with the radius of bending.

The critical radius of curvature, $R_{c}$, is defined as

$R_{c}=\frac{3 n_{2} \lambda}{4 \pi(N A)^{3}}$

where $R_{c}$ is the critical radius of bending, $n_{2}$ is the refractive index of the cladding, $N A$ is the numerical aperture of the fiber, and $\lambda$ is the wavelength $[1,2]$.

\section{COMSOL SIMULATIONS}

In COMSOL, 2D U-shape fiber optics rectangular and semicircle are generated as the geometry of the model. All parameters are tabulated in Table 1.

Table- I: Parameter of U-shape fiber optic

\begin{tabular}{lccc}
\hline \multicolumn{1}{c}{ Study } & $\begin{array}{c}\text { Core diameter } \\
(\boldsymbol{\mu m})\end{array}$ & $\begin{array}{c}\text { Cladding } \\
\text { diameter } \\
(\boldsymbol{\mu m})\end{array}$ & Loop \\
\hline Effect of mesh sizes & 9 & 125 & 1 \\
Effect of curvature radius & 9 & 125 & 1 \\
Effect of turn number & 9 & 125 & 1 to 9 \\
Effect of core diameter & 9 & 125 & 1 \\
& 4 & 125 & 1 \\
& $50-9-50$ & 125 & 1 \\
& $62.5-9-62.5$ & 125 & 1 \\
& $50-4-50$ & 125 & 1 \\
& $50-9-50$ & 125 & 1 \\
\hline
\end{tabular}

In this simulation, we solve the wave equation using electromagnetic wave in the wave optics module [3]. The electric field for the wave can be written as

$\boldsymbol{E}(\boldsymbol{r})=\boldsymbol{E}_{1}(\boldsymbol{r}) e^{\left(-j \boldsymbol{k}_{1} \cdot \boldsymbol{r}\right)}$

for the wave vector set to unidirectional, where $E_{1}$ is a slowly varying field envelope function, and $\Phi$ approximates the propagation phase for the wave. Inserting this electric filed formulation into Maxweel's equation results in following wave equation for the envelope function

$\left(\nabla-j \boldsymbol{k}_{1}\right) \times\left(\left(\nabla-j \boldsymbol{k}_{1}\right) \times \boldsymbol{E}_{\mathbf{1}}\right)-k^{2} \boldsymbol{E}_{\mathbf{1}}=0$

For time-harmonic and eigenfrequency problems. The wave number, $k$ is defined by

$k=k_{o} n$

where $n$ is the refractive index and the wave number of free space, $k_{o}$ is defined

$k_{o}=\omega \sqrt{\varepsilon_{o} \mu_{o}}=\frac{\omega}{c_{o}}$

\section{RESULTS AND DISCUSSION}

In the part hereof, the influence of the selected mesh size, core diameter, curvature radius, $R$ and number of turns, $N$ on the losses of bend fiber was investigated.

\section{A. Effect of mesh selection}

Free mapped mesh element was chosen and calibrated for the U-shape fiber optics. All mesh sizes, including extremely fine, extra fine, finer, fine, normal, coarse, coarser, extra coarse, and extremely coarse, were used to determine which size can generate a perfect result for all bending fiber optics (i.e., fine mesh). Fig. 1 shows the mesh of the U-shape fiber optic geometry and the electric field with different mesh sizes. Clearly, the selected (best) mesh size for simulation provided the best solution for determining the best objective. Although the extremely fine mesh is a good mesh, it did not achieve the desired outcome for this study. Fig. 2 clearly shows which power flow at Port 2 is the smallest, which is irrelevant to this study. Extremely coarse, extra coarse, coarser, coarse, and normal meshes are unsuitable for this geometry. Although the power flow output was high using an extremely coarse mesh, this mesh is unsuitable. Meanwhile, the power flow at the output port, using extra coarse, coarser, coarse, and normal of meshes, was larger than that at the input port, which is illogical. It is because of the shape of bending fiber not smooth and it will ignore then affect the propagating light at the curve geometry. Generally, macro bending affects the propagating light and shows that the modes at the curve section exit the core. Fine and finer meshes show the real outcome of this situation. Therefore, the mesh size must be selected based on the geometry and the length of the geometry. The result is perfect when using an extremely fine mesh for long fibers. It means each mesh component is a set of characteristics equations shall be governed that describe the fiber supported modes in its calculation [4].
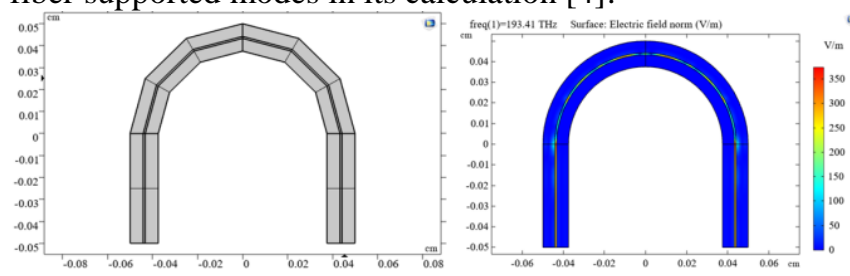

(a)

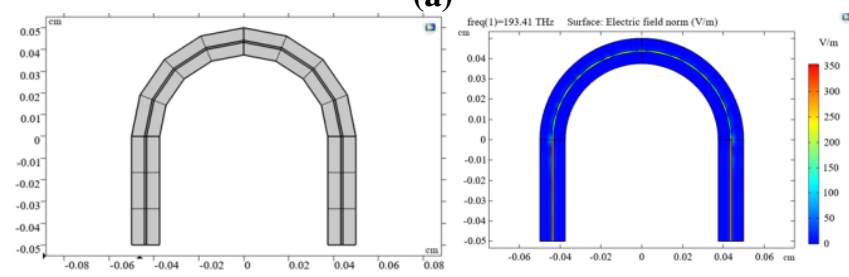

(b)

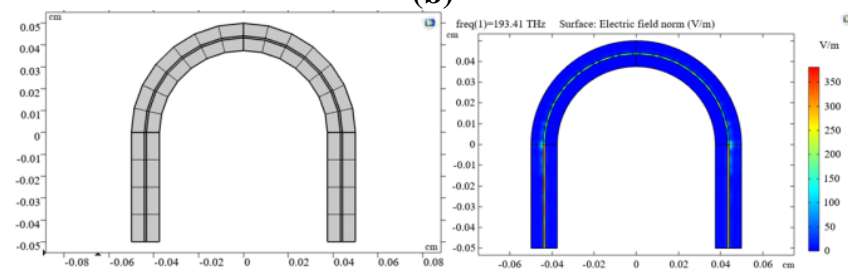

(c)

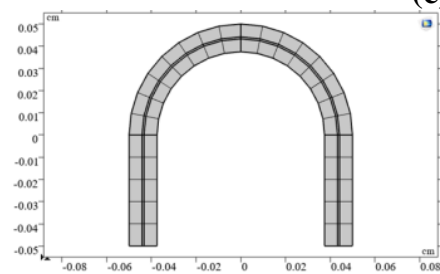

(d)
Published By:

Blue Eyes Intelligence Engineering and Sciences Publication (c) Copyright: All rights reserved. 


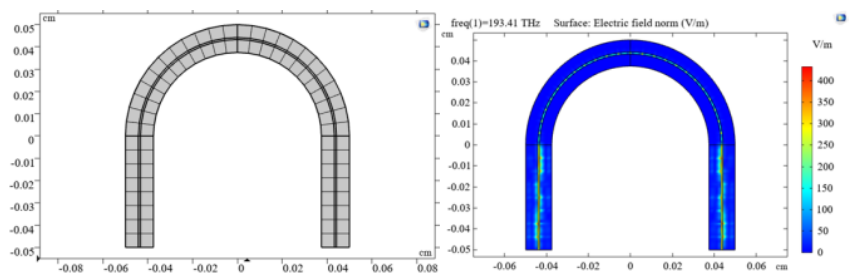

(e)
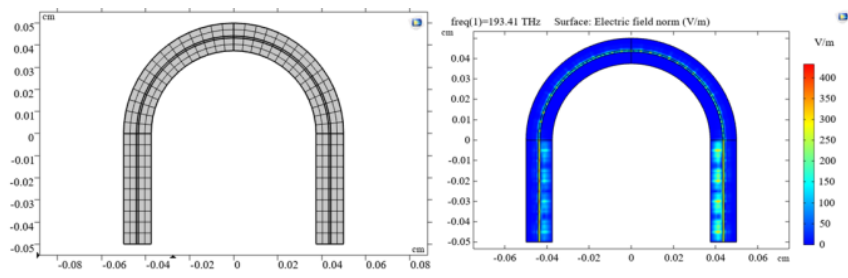

(f)

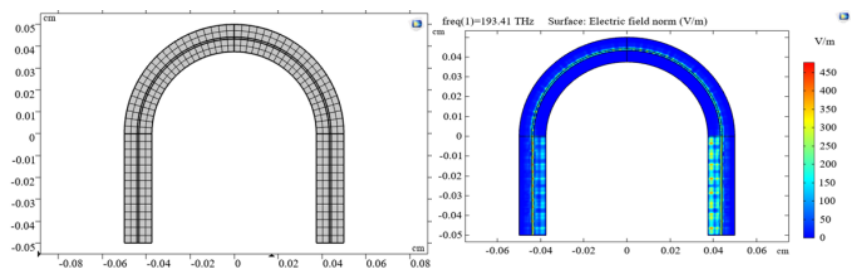

(g)

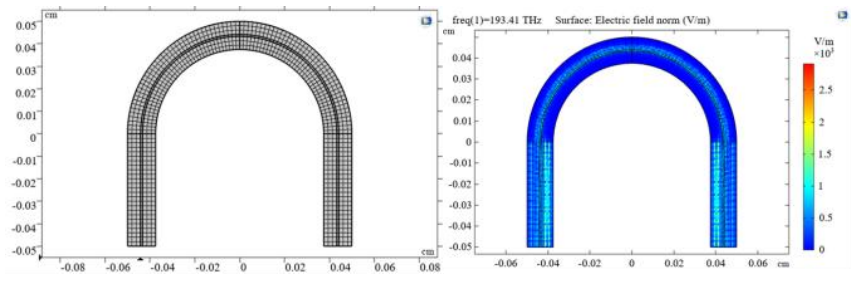

(h)

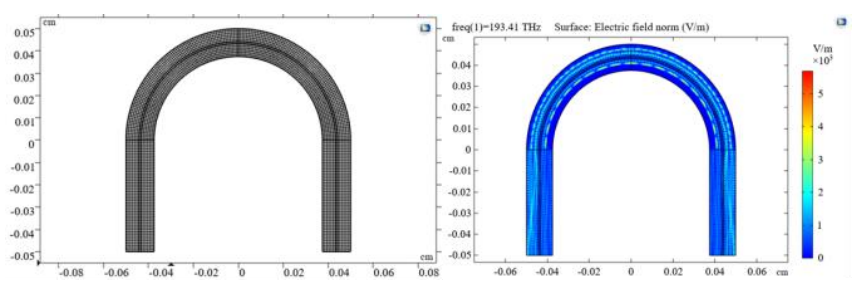

(i)

Fig. 1. U-shape fiber optic geometry with (a) extremely coarse and (b) extra coarse (c) coarser (d) coarse (e) normal (f) fine (g) finer (h) extra fine (i) extremely fine meshes

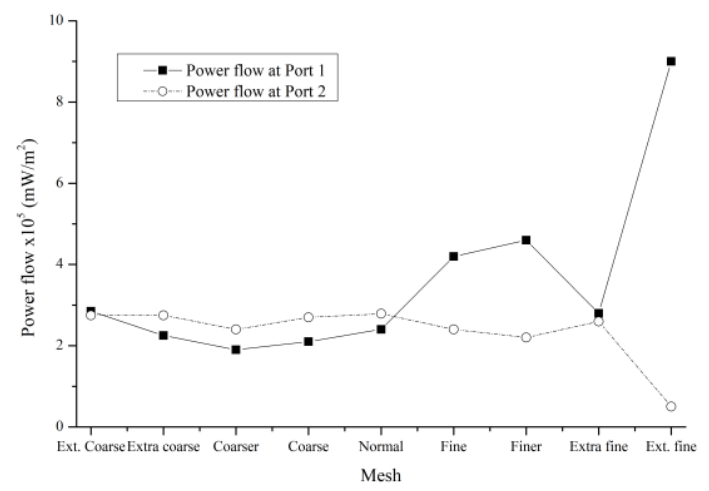

Fig. 2. Power flow at Port 1 (Input) and Port 2 (Output) with different meshes

\section{B. Effect of curvature radius}

The power flow at radius of curvature $\mathrm{R}=0.5,0.75,1.0$,

Retrieval Number: 100.1/ijeat.B20821210220

DOI:10.35940/ijeat.B2082.1210220

Journal Website: www.ijeat.org
$1.25 \mathrm{~cm}$ was investigated by examining the power flow at the input and output ports. In this geometry, the length of the U-shaped fiber is longer than geometry in effect on mesh size. Therefore, extreme mesh was selected to ensure that the results are near the real values. The core and cladding sizes for this study are 9 and $125 \mu \mathrm{m}$, respectively. To ensure that the range of bending radius is not equal to the critical radius, the minimum critical bend radius of the single mode fiber with negligible loss is obtained at $R_{c} \approx 100 \mathrm{~mm}$ according to the following equation

$R_{c} \approx \frac{20 \lambda}{\sqrt[3]{\Delta_{n}}}\left[2.748-0.996\left(\frac{\lambda}{\lambda_{c}}\right)\right]^{-3}$

where $\lambda$ and $\lambda_{c}$ are the operating and cut-off wavelengths, respectively [5]. Thus, the curvature radius ranging from 0.5 $\mathrm{cm}$ to $1.25 \mathrm{~cm}$ at the operating wavelength of $1550 \mathrm{~nm}$ is valid for use in this study. On one hand, if the bend radius is greater than the critical value, then the bending is insensitive macro bending. In this situation, the photon in the propagated bend light wave moves in a circular path with the axis of bending. On the other hand, if the bend radius is below the critical value, the bend loss will increase rapidly because the phase velocity of the outer part of the fiber is equal to the light velocity in the cladding. However, it cannot be more than the light velocity in the cladding. This mechanism allows the construction of a relatively sensitive bending fiber sensor. Table 2 shows the power flow for all curvature radii. Clearly, the input power is greater than the output power.

Table- II: Power flow at Port 1 (Input) and Port 2 (Output) with R values of $0.5 \mathrm{~cm}, 0.75 \mathrm{~cm}, 1.0 \mathrm{~cm}$, and $1.25 \mathrm{~cm}$ at $1550 \mathrm{~nm}$.

\begin{tabular}{ccc}
\hline \multicolumn{2}{c}{$\begin{array}{c}\text { Curvature Radius } \\
\text { (cm) }\end{array}$} & \multicolumn{2}{c}{ Power flow $\left(\mathbf{m W} / \mathbf{m}^{2}\right)$} \\
\cline { 2 - 3 } & Port 1 & Port 2 \\
\hline 0.50 & $1.25 \times 10^{6}$ & $0.28 \times 10^{6}$ \\
0.75 & $4.20 \times 10^{5}$ & $2.70 \times 10^{5}$ \\
1.00 & $3.52 \times 10^{5}$ & $2.85 \times 10^{5}$ \\
1.25 & $3.25 \times 10^{5}$ & $2.79 \times 10^{5}$ \\
\hline
\end{tabular}

The variation of power loss against the radius of curvature is illustrated in Fig. 3. The results in Fig. 3 indicate that high bending loss is induced by a small bend radius. The measured bending loss in this simulation at different curvature radii fits the following equation

$L_{R}=\xi_{R 1} e^{\left(-\xi_{R 2} R\right)}$

where $L_{R}$ is the bending loss for various bend radii, while $\xi_{1}$ and $\xi_{2}$ are the fitting parameters [2]. The curve shows good agreement. Thus, the simplified formula can be used to estimate the bending loss for the bend fiber sensor at various bend radii.

Published By:

Blue Eyes Intelligence Engineering and Sciences Publication

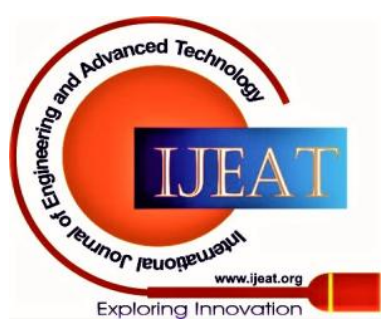




\section{D Propagation Simulation of Variation Parameters of U-shape Fiber Optic}

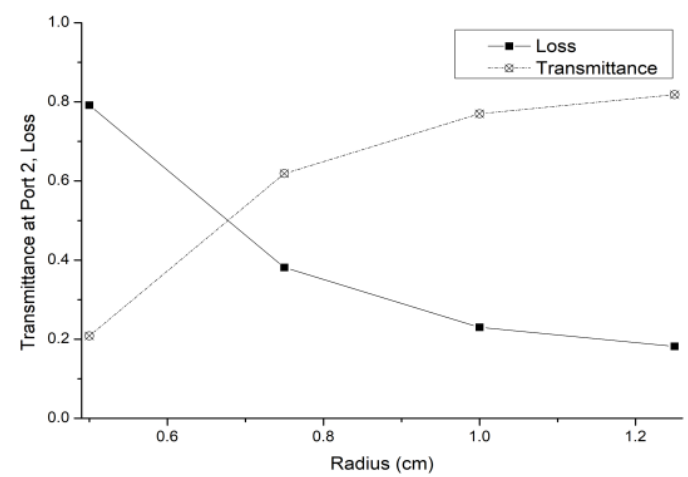

Fig. 3. Relationship between the bend loss and the corresponding bend radius at $1550 \mathrm{~nm}$

\section{Effect of core diameter}

In this study, macro bending was analyzed at core diameters of 9, 4, 50-9-50, 50-4-50, 62.5-9-62.5, and $62.5-4-62.5 \mu \mathrm{m}$. Fig. 4 shows the power flow at the input and output ports of the bending fiber optic for different core diameters. The figure shows that the fiber optic with a core diameter of $4 \mu \mathrm{m}$ generated a higher loss than that with a core diameter of $9 \mu \mathrm{m}$. The same is true with the fiber optic with the hetero-core combinations of $4 \mu \mathrm{m}$ with 50 and $62.5 \mu \mathrm{m}$. The single mode in the transmission fiber partially leaks into the cladding at the boundary interface between the transmission fiber $(50 \mu \mathrm{m}$ or $62.5 \mu \mathrm{m})$ and the hetero-core part $(4 \mu \mathrm{m}$ or $9 \mu \mathrm{m})$. In this case, the core diameter of $9 \mu \mathrm{m}$ could be large enough to support single mode propagation, and most of the power can pass through this region compared with the core diameter of $4 \mu \mathrm{m}$. Thus, the $9-\mu \mathrm{m}$ core diameter has a low-insertion loss type and generates more power at the output port. Meanwhile, the 50-4-50- and 62.5-4-62.5-um combinations can be categorized as high sensitivity types of fiber optic. In other words, single mode propagation in the transmission line easily collapses at the interface of the multimode and single mode fiber optics at the wavelength of $1550 \mathrm{~nm}$. After passing through the second interface of the single-mode and multimode fiber optics, all the light modes are coupled back to multimode [6, 7]. However, recoupling in this part could be very sensitive to the change in radius of curvature due to macro bending [8]. Generally, the fiber size and the index of refraction are the common key factors that impact light travel in a fiber. It causes limited discrete modes that are determined by the wavelength of the light. The normalized frequency can be written as

$V=\frac{2 \pi a}{\lambda} \sqrt{n_{\text {core }}^{2}-n_{\text {clad }}^{2}}$

where $a$ is the core diameter of the fiber, $\lambda$ is the wavelength of the propagating light wave, and $n_{\text {core }}$ and $n_{\text {clad }}$ are the refractive indexes of the fiber core and cladding, respectively [9].

For the hetero-core fiber structure of $50-9-50 \mu \mathrm{m}$, the normalized frequency is approximately 21.29 in the multimode and 2.33 in the hetero-core part, while the numbers of supported modes are 226.63 and 2.71, respectively. In the calculated mode, the supported mode in the core was trimmed down from its original value when it passed through the first interface part (from $50 \mu \mathrm{m}$ to $9 \mu \mathrm{m}$ ). Then, the light wave was coupled into the cladding modes at the single mode region. Then, at the second interface (from $9 \mu \mathrm{m}$ to $50 \mu \mathrm{m}$ ), the energy of the propagating modes in the multimode region was coupled with those from both the cladding and core modes in the single mode fiber. This situation also happened in the other hetero-core fiber optic combinations, namely, 50-4-50, 62.5-4-62.5, and 62.5-9-62.5 $\mu \mathrm{m}$. Therefore, the number of modes decreases with the fiber diameter, except at the core diameter of $4 \mu \mathrm{m}$. The fiber optic with a core diameter of $4 \mathrm{um}$ is the special fiber, which is all-glass highly bend-insensitive, with a large numerical aperture of $0.29-0.31$.

Table 3 shows the number of modes for $4,9,50$, and 62.5 $\mu \mathrm{m}$ at the wavelength of $1550 \mathrm{~nm}$.

Table- III: Power flow at Port 1 (Input) and Port 2 (Output) for core diameters $9 \mu \mathrm{m}, 4 \mu \mathrm{m}, 50-9-50 \mu \mathrm{m}$, 50-4-50 $\mu \mathrm{m}, 62.5-9-62.5 \mu \mathrm{m}$, and 62.5-4-62.5 $\mu \mathrm{m}$ at the wavelength of $1550 \mathrm{~nm}$.

\begin{tabular}{ccc}
\hline Core diameter $(\boldsymbol{\mu m})$ & \multicolumn{2}{c}{ Power flow $\left(\mathbf{m W} / \mathbf{m}^{\mathbf{2}}\right)$} \\
\cline { 2 - 3 } & Port $\mathbf{1}$ & Port $\mathbf{2}$ \\
\hline 9 & $3.9 \times 10^{5}$ & $2.6 \times 10^{5}$ \\
4 & $2.35 \times 10^{5}$ & $0.1 \times 10^{5}$ \\
$50-9-50$ & $1.8 \times 10^{5}$ & $0.81 \times 10^{5}$ \\
$50-4-50$ & $3.39 \times 10^{5}$ & $0.1 \times 10^{5}$ \\
$62.5-9-62.5$ & $1.29 \times 10^{5}$ & $0.13 \times 10^{5}$ \\
$62.5-4-62.5$ & $2.38 \times 10^{5}$ & $0.17 \times 10^{5}$ \\
\hline
\end{tabular}

Table- IV: V-number and number of modes for $9,4,50$, and $62.5 \mu \mathrm{m}$

\begin{tabular}{cccc}
\hline Diameter & Wavelength & V-number & Number of Modes \\
\hline $9 \mu \mathrm{m}$ & $1550 \mathrm{~nm}$ & 2.33 & 2.71 \\
$4 \mu \mathrm{m}$ & $1550 \mathrm{~nm}$ & 2.47 & 3.05 \\
$50 \mu \mathrm{m}$ & $1500 \mathrm{~nm}$ & 21.29 & 226.63 \\
$62.5 \mu \mathrm{m}$ & $1550 \mathrm{~nm}$ & 37.72 & 711.39 \\
\hline
\end{tabular}

\section{Effect of turn number}

In this section, the impacts of $\mathrm{N}$ on bending loss are considered. A fiber optic with nine U-shape is modelled on COMSOL as shown in Fig. 4. The core and cladding diameters in this study are 9 and $125 \mu \mathrm{m}$, respectively. The variation of power flow against the $\mathrm{N}$ for bending radius $\mathrm{R}=$ $0.5,0.75,1.0,1.25 \mathrm{~cm}$ is shown in Fig. 5. Clearly, the power flow decreases as $\mathrm{N}$ increases. In other words, the loss increases the $\mathrm{N}$ of the $\mathrm{U}$-shape.

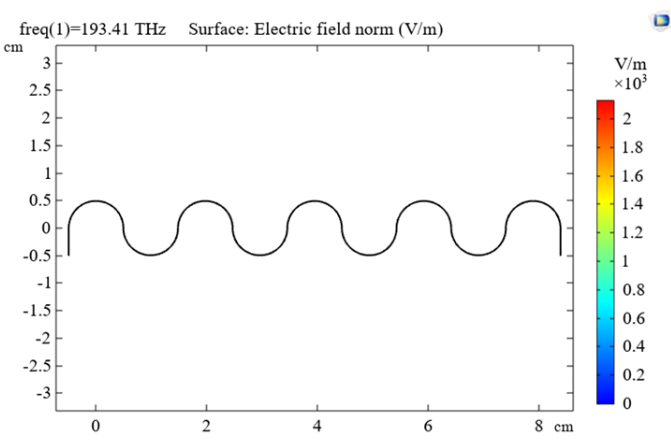

Fig. 4. Nine of U-shape fiber optic for study the impact of turn number

Published By:

Blue Eyes Intelligence Engineering and Sciences Publication (C) Copyright: All rights reserved. 


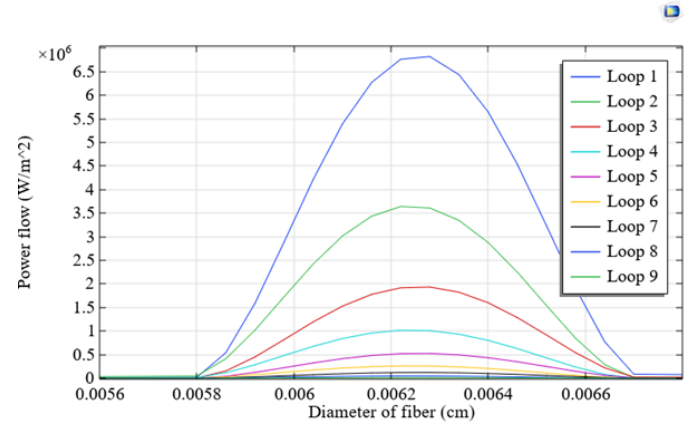

(a)

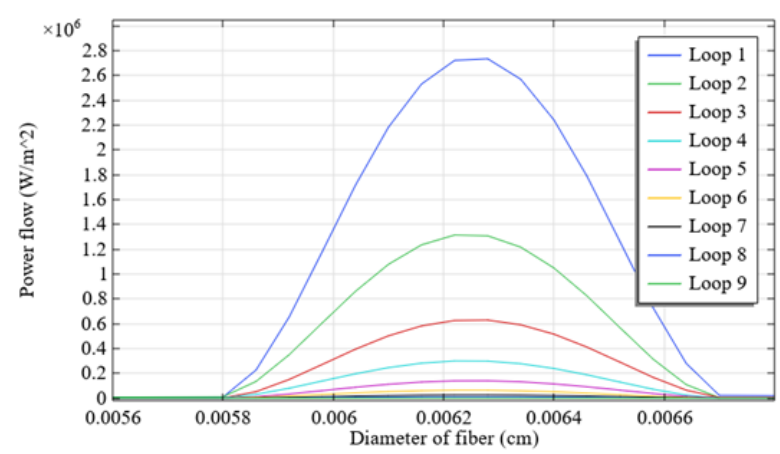

(b)

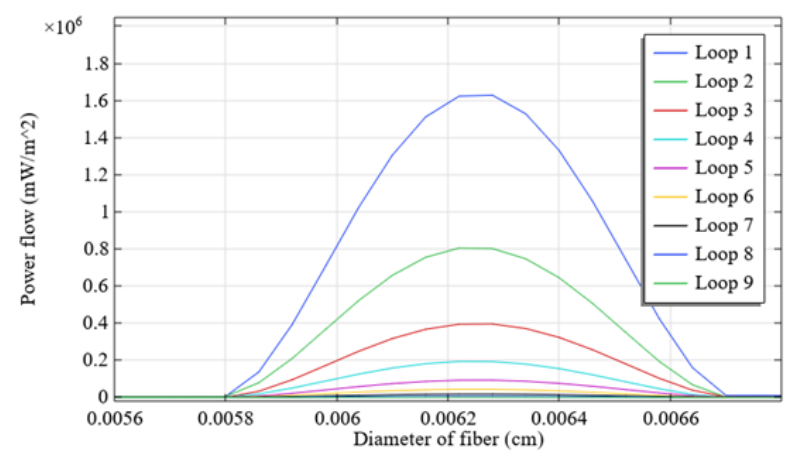

(c)

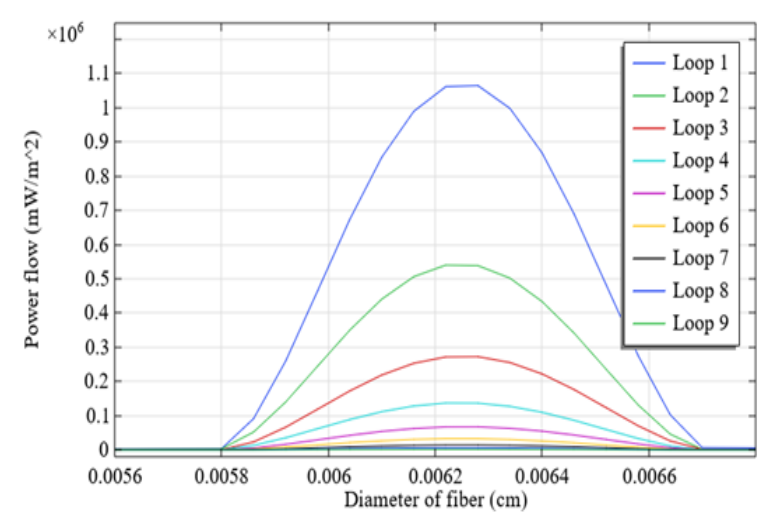

(d)

Fig. 5. Variation of power loss with the macro bending loop (Loops 1 to 9) for R (a) $0.5 \mathrm{~cm}$ (b) $0.75 \mathrm{~cm}$ (c) $1.0 \mathrm{~cm}$ and (d) $1.25 \mathrm{~cm}$

\section{CONCLUSION}

The bend fiber was studied by simulation using COMSOL Multiphysics via the wave optic module. The power flow gratefully acknowledged. Electronics Engineering. obtained at the input and output ports of U-shaped fiber optics indicates that mesh size affects the simulation outcome. Further investigation also shows that the power flow at the output port decreases as the curvature radius decreases and the turn number increases. Moreover, decreasing the $\mathrm{V}$-number by reducing the $\Delta n$ will reduce the number of modes and affect the output of fiber optics. The presented preliminary results of the numerical simulation of bend fiber additional coating on the fiber surface.

\section{ACKNOWLEDGMENT}

Authorsare thankful to Photonic Lab, Institute of Microengineering and Nanoelectronics (IMEN), UKM for providing facilities. Financial support from the Ministry of Education (MOE) and Universiti Malaysia Sarawak are

\section{REFERENCES}

1. M. F. M. Salleh and Z. Zakaria, "Effect of bending optical fibre on bend loss over a long period of time,". ARPN Journal of Engineering and Applied Sciences, 2015 Parameters of Fiber-Optic Bend for Sensing Applications," Internationa 107-112

3. Wave Optics Module Users Guide, COMSOL Multiphysics v. 5.2,COMSOL AB, Stockholm, Sweden, 2015. [Online]. Available:www.comsol.com

4. A. K. Shah and R. Kumar, "Design and simulation for highly nonlinear solid core photonic crystal fiber," International Journal of Engineering and Advanced Technology., 2019

5. Alemdar, K., Likoglu, S., Fidanboylu, K. \& Toker, O. 2013. A novel periodic macrobending hetero-core fiber optic sensor embedded in textiles. ELECO 2013 - 8th International Conference on Electrical and

6. R. Biswas, P. Karmakar, C. Gogoi,and D. Sarma, “ A Comparative Analysis of Hetero Core Spliced MSM and SMS System in terms of Transmittance," International Journal of Photonic and Optical Technology. Vol. 3, Iss, pp: 16-19, sept. 2017 sensing with hetero-core fiber specklegram," Photorefractive Fiber and Crystal Devices: Materials, Optical Properties, and Applications X, 2004

K. Watanabe, K. Tajima, and Y. Kubota, "Macro bending and liquid detection," IEICE Transactions on Electronics, 2000.

9. A. Dutta, "Mode analysis of different step index optical fibers at 1064 nm for high power fiber laser and amplifier," IJECT, vol. 6, 2015

\section{AUTHORS PROFILE}

Noor Azie Azura Mohd Arif received the Bachelor of Engineering in Microelectronics Engineering and Master of Science from Universiti Kebangsaan Malaysia, Postgraduate Diploma (Teaching and Learning) from Universiti Malaysia Sarawak. She started joined Universiti Malaysia Sarawak since January 2011 and present as a lecturer. Her areas of research are developing of $\mathrm{ZnS}$ nanoparticle with spin coating method and modelling of ZnS nanoparticle by self-assembled approach. Presently, she is pursuing Doctor of Philosophy with Institute of Microengineering and Nanoelectronics (IMEN), Universiti Kebangsaan Malaysia, in the field of fiber optic.

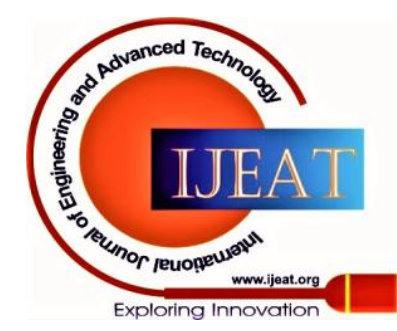


Abang Annuar Ehsan works as a research fellow at the Institute of Microengineering and Nanoelectronics, Universiti Kebangsaan Malaysia (UKM). He holds a BE (Elec. Eng., UNSW, Australia), MSc (Microelectronics, UKM), ME (Manufacturing System Engineering, UPM), MPM (Project Management, OUM), PhD (Applied Science, UiTM) and PhD (Microengineering and Nanoelectronics, UKM). His research interest includes fiber optics devices, optical design, additive manufacturing, and micromachining processes. He has published his works in journals such as Optical Engineering, Optical Review, Optica Applicata, Electronics Express and IEEE Access.

Dr. Abang Annuar Ehsan is a registered professional engineer (P.Eng.) under the Board of Engineers Malaysia and also a project management professional (PMP) under the Project Management Institute.

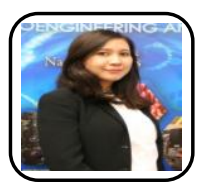

Dilla Duryha Berhanuddin works as a senior lecturer at the Institute of Microengineering and Nanoelectronics, Universiti Kebangsaan Malaysia (UKM). She holds a ME (Meng in Electronics Engineering) and $\mathrm{PhD}$ (Silicon Photonics) form University of Surrey, UK. Research interest on silicon light-emitting device, optical and structural characterization, and damage engineering in silicon lattice.

Published By:

Blue Eyes Intelligence Engineering and Sciences Publication 